\title{
Antimicrobial Activity of Breast Milk against Neonatal Pathogens
}

\section{Aakhila $\mathrm{A}^{*}$ and Feminamol V M}

Student, Department of Microbiology, presentation college of applied sciences, Puthenvelikkara, Ernakulam, Kerala, India

*Corresponding Author: Aakhila A, Student, Department of

Microbiology, presentation college of applied sciences, Puthenvelikkara, Ernakulam, Kerala, India.
Received: February 18, 2021

Published: March 29, 2021

(C) All rights are reserved by Aakhila A and

Feminamol V M.

\section{Abstract}

Breast milk is a nourishment and medicinal shield for the new born. Its various benefits include strengthening baby's immune system, anti-inflammatory functions, lowering the risk of allergies, mental ailments etc.

In this study the antimicrobial activity of breast milk against some neonatal pathogens (Staphylococcus aureus and Candida albicans) were evaluated. Antibacterial activities of different antibiotics were tested using Kirby Bauer disc diffusion method. Breast milk from different mothers as well as cow milk were subjected to antimicrobial assay by agar well diffusion. Result showed that the breast milk has antibacterial activity against the tested organisms compared to cow milk which have no antibacterial effect.

Keywords: Breast Milk; Neonatal Pathogens; Antibacterial Effect

\section{Introduction}

Human milk contains many of biologically active components that contribute to the short- and long-term benefits of breast feeding. Breast milk is a nourishment and medicinal shield for the new born. Its various benefits include strengthening baby's immune system, lowering risk of allergies, chronic diseases, mental ailments etc. [16]. Human milk contains several factors that serve to shield the infants against numerous bacteria, viruses, and fungi [20]. Its antibacterial effect due to the presence of antimicrobial peptides (AMP) like lactoferrin, alpha defensins, beta defensin, lysozyme, lacto-peroxidase [8].

Breast milk contains higher levels of AMP than those present in formula feed or cow milk. All these factors in breast milk lower the occurrence of number of bacterial infections in babies such as ear infection, respiratory illnesses, and diarrhea [30]. Lactose in breast milk is a source of energy for the infant. Other than lipids and lactose, human milk oligosaccharides (HMOs) are the third most abundant components of human breast milk.

HMOs are diverse, conjugated short chain and long chain glycans 93 - 15 monosaccharide units found at concentrations of 20 - $25 \mathrm{~g} / \mathrm{L}$ in the colostrum, the first milk, to $5-20 \mathrm{~g} / \mathrm{L}$ in the mature milk. The diversity, complexity and concentration of HMOs are unique to humans, and cannot be provided by milk of domestic animals such as cows, sheep or goats. The concentration and composition of HMOs is individual and varies during the period of lactation, complimenting the needs of infant [22]. In addition to their prebiotic effects on beneficial bacteria, HMOs also directly deter colonization by pathogens (not only bacteria but also virus) by acting as anti-adhesive antimicrobials. The protective mechanism of HMO has been reported for several diarrhoea causing pathogens such as Campylobacter jejuni and Salmonella fyris, but also against pathogenic Escherichia coli, Pseudomonas aeruginosa and Strepto- 
coccus pneumoniae. HMOs even show antimicrobial activity against pathogenic Staphylococcus aureus and Acinetobacter baumannii, the major source of nosocomial infections [1]. Neonatal sepsis is a significant cause of morbidity and mortality among neonates worldwide [31]. It may occur through transplacental infection [17]. Neonatal sepsis is categorized into early and late onset sepsis. Early onset neonatal sepsis (EONS) occurs within 72, while the lateonset neonatal sepsis (LONS) occurs between $72 \mathrm{~h}$ to 90 days [29]. The bacterial agents involved in early-onset sepsis include group B Streptococcus (GBS), Escherichia coli, coagulase negative Staphylococcus, Haemophilus influenzae and Listeria monocytogenes [33]. The organisms involved in the late-onset sepsis include coagulase negative staphylococci (CONS), Staphylococcus aureus, Klebsiella pneumoniae, Escherichia coli etc. [12].

Standard treatment of neonatal sepsis includes the use of antimicrobial agents. Antibiotics are continued, changed, or discontinued depending on the laboratory test results; extend of clinical suspicion and cultures [21]. Use of appropriate antibiotics according to bacterial profile and culture sensitivity results would minimize the risk of severe morbidity and mortality and help in reducing the emergence of multidrug-resistant organisms [6].

The present study was carried out to determine the antibacterial effect of human breast milk against common neonatal pathogens and common isolates of neonatal sepsis.

\section{Review of Literature}

Breast milk is considered to be the best source of infant growth and nutrition. Evidences convey that breast milk contains a variety of bioactive agents that improve the function of the gastrointestinal tract, the immune system, brain development. Thus, breast milk is necessary for optimal infant growth and development. Recently, studies have further suggested that breast milk reduces infant late metabolic diseases, protecting against obesity and type 2 diabetes [27]. Fatty acids present in breast milk has antimicrobial function in the intestinal tract. Interestingly, fatty acids found in algae also have antimicrobial activity against both gram-positive and gramnegative bacteria [10]. The intrinsic components of milk have local antipathogenic effects that supplement the infant's innate immunity. This includes substances such as free fatty acids (FFA), monoglycerides, antimicrobial peptides (AMP), which bind diarrheal pathogens [26].
In addition to these, there are other factors present in the breast milk support infant's immune system including bifidus factor, lysozyme, lactoperoxidase, lactoferrin, lipoprotein, lipase. epidermal growth factor in breast milk may stimulate the maturation of the gastrointestinal epithelium as a barrier. There is convincing evidence that breast feeding may reduce the incidence of gastrointestinal infections [19]. In a study, the protective effect of breast feeding against enterovirus infections was primarily mediated by maternal antibodies in breast milk [24]. In addition, infants who were breast fed for $>4$ month showed a three times reduced incidence of severe respiratory tract infection, as compared with infants who were not breast fed [3]. Breast milk also provides protection against otitis media and urinary tract infections [15].

Neonatal sepsis is classified into "early onset" if it occurs within the first week and as "late onset" if occurring after the first week until the end of the neonatal period [14]. The findings of this review suggest that Klebsiella spp, E. coli, and S. aureus are major causes of infections the first week of life. However, data for the first week of life from community settings are particularly scarce, and the contribution of environmental factors in the causation of infection among hospital born babies cannot be excluded. Beyond the first week of life-although based on relatively few reports of community-acquired infections- $E$. coli, GBS, and $S$. aureus, as well as $S$. pneumoniae, $S$. pyogenes, and Salmonella spp are commonly isolated [32].

A similar preponderance of gram-negative organisms and S. aureus is also noted in home-delivered babies, although data again were extremely limited. From the WHO-sponsored YIS study from Philippines, the authors [7] also note a predominance of gram-negatives among home-delivered babies (76\% of 21 babies), although the etiological break up was not presented.

Although GBS-relative to other organisms and relative to data from industrialized countries [23] - were not as frequently reported, particularly in the first week of life, they appear common in African countries and very uncommon in the South Asian region. However, intercountry variations are also apparent, with some South Asian reports suggesting higher prevalence of GBS and some African reports the converse, or even no GBS isolates [13]. The reasons for such inter-regional variations are not clearly understood, and variations in risk factors such as vaginal colonization, strain virulence, antibody levels, or cultural practices are thought to contribute [2]. 
Among pathogens in the 7 to 59-day period, only a limited number of facility-based studies clearly attempted to exclude hospitalacquired infections. These data were dominated by a single Malawian study [18] and more than half of remaining data were from multicenter Young Infant Studies (YIS) and rural Kenya [4]. Data from YIS indicated that S. pneumoniae, S. aureus, E. coli, S. pyogenes, and nontyphoidal Salmonella species were important pathogens beyond the first week of life, whereas in Kenya and Malawi, in addition to above pathogens, GBS were also common. The spectrum in the late onset age group can, in general, be considered a transitional phase between neonatal and post neonatal periods-where organisms associated with neonatal sepsis (S. aureus, E. coli, GBS), as well as those associated with post neonatal sepsis (S. pyogenes, $S$. pneumoniae), are equally important. It is worth noting that published information on community-acquired sepsis in the late neonatal and post neonatal period from South Asia is strikingly absent, although this region contributes very heavily to the global burden of neonatal and child mortality.

Staphylococcus aureus is a facultative anaerobic Gram-positive bacterium whose incidence ranges from skin, soft tissue, endovascular to wound infections. Candida albicans is an opportunistic fungus that can cause superficial, localized, and systemic infection. Gram-positive pathogens played a major role in etiology of sepsis in the post neonatal and early infant period and $S$. pneumoniae emerged as the single most important pathogen in this age group. Other important pathogens in this group included Salmonella species and Haemophilus influenzae. H. influenzae are almost certainly under-estimated, especially in South Asia because of inadequate bacteriological laboratory resources to isolate this fastidious pathogen, and frequent use of antibiotics by children before submitting specimens for culture. Indeed, S. pneumoniae, H. Influenzae, and Salmonella are frequently reported in etiology of pneumonia, meningitis, and septicemia in children under 5 years of age from African and South Asian countries, and from other regions, especially when nonculture methods such as antigen detection are used [25]. However, the post neonatal and early infant groups are often excluded or not disaggregated from infant age groups. All of these factors contribute to the paucity of data available in this age group category. Both gram-positive and gram-negative isolates showed a high resistance to cephalosporins, penicillin, and amoxyclav in the current study, it was observed that antibiotic resistance among the gram-positive isolates was highest to penicillin (87\%) followed by amoxyclav (66\%). Similar reports of high resistance to ampicillin
(71\%) were reported by [5]. All the gram-positive isolates were sensitive to vancomycin similar to a study by [33] in the present study, $41 \%$ S. aureus isolates were found to be methicillin-resistant, compared to $11.1 \%$ reported by [12]. Gram-negative isolates showed a high resistance to all cephalosporins which is similar to the resistance pattern reported by Klebsiella pneumoniae. showed resistance to all antibiotics tested except imipenem. In our study, the $48 \%$ were ESBL producers as compared to $72 \%$ as reported by [5].

Neonatal septicemia is a life-threatening situation therefore rapid treatment with antibiotics is essential. Treatment of neonatal sepsis mainly with amoxicillin and aminoglycoside. S. aureus and gram-negative isolates were found to be resistant to amoxicillin and aminoglycoside. So selection of antibiotic is the key step in the treatment. In the view of above the strategy of antibiotic usage in the hospital must be reviewed [28].

\section{Objectives of the Study}

- To isolate pathogens from neonates.

- To determine the antibacterial efficacy of antibiotics against neonatal pathogens.

- To determine the antibacterial efficacy of human breast milk and cow milk against common neonatal pathogens.

\section{Materials and Methods}

\section{Sample collection}

Oral, pus and ear swabs from nearby locality and hospitals were taken. Swabs were pooled in nutrient broth tubes.

\section{Isolation of neonatal pathogens}

Materials required

- Clinical specimens

- Nutrient broth

- Nutrient agar (Himedia Laboratories Pvt. Ltd. Mumbai)

- Sabouraud dextrose agar (Himedia Laboratories Pvt. Ltd. Mumbai).

\section{Isolation}

Clinical specimens were streaked on nutrient agar plates and incubated at $37^{\circ} \mathrm{C}$ for 24 hours. Colonies so obtained on nutrient agar plates were further inoculated into peptone water and identified on the basis of: 
- Microscopic analysis - Gram staining

- Colony morphology

- Biochemical reactions such as catalase test, coagulase test, mannitol salt agar, germ tube test (identification of yeast cell) etc.

Strains were then stored as slant at $4^{\circ} \mathrm{C}$ till use.

\section{Biochemical reactions}

Catalase test

- The test was performed on a clean glass slide.

- A drop of hydrogen peroxide added to the slide.

- Then pick a colony using end of a glass slide and added to the drop.

- Then observed for the effervescence [11].

\section{Coagulase test}

- The coagulase test was performed in a slide.

- A drop of Saline added at one end as control and human plasma added to another end.

- With the end of glass slide emulsified a portion of the isolated colony in each drop to make two thick suspensions.

- After gentle mixing clumping was observed in the plasma added colony [11].

\section{Identification of yeast}

Germ tube test

- Yeast cells were inoculated into $0.5 \mathrm{ml}$ of human serum and incubated at $37^{\circ} \mathrm{C}$ for $3 \mathrm{~h}$.

- After this period using a loop drop of suspension added on a slide and covered with coverslip.

- Germ tube was observed microscopically (at 40X).

Antimicrobial susceptibility test (Kirby Bauer disc diffusion method).

Antimicrobial susceptibilities of isolated pathogens to the selected antimicrobial agents were determined (CLSI).

Materials required

- Clinical isolates

- Peptone water
- Mueller Hinton agar plates

- Cotton swab

- Antibiotic discs.

Procedure

- A pure culture plate of isolates to be tested and emulsified a colony from the plate in the sterile peptone solution.

- A sterile swab was dipped into the broth culture of organism and gently squeezed against the inside of the tube in order to remove excess fluid in the swab.

- Using the swab, a lawn culture was prepared on the MHA plate and allowed to dry for 5 minutes.

- Antibiotic discs were placed on the surface of the agar using sterilized forceps.

- Incubated for 24 hours at $37^{\circ} \mathrm{C}$.

- After incubation, using a metric ruler the diameter of the zone of inhibition for each antibiotic used was measured.

- Compared the measurement obtained from the individual antibiotics with the standard table to determine the sensitivity zone.

\section{Collection of milk sample}

- Breast milk was collected from mothers in the locality.

- After hand washing and cleansing of the breast with soap and tap water, milk samples were collected manually into sterile screw caped tubes, labelled and stored at $4^{\circ} \mathrm{C}$ till further use.

- Cow milk sample was collected from the farm house.

- After giving proper instructions about the asceptic practices to the milker, the cow milk sample was collected in sterile screw capped bottles and stored at $4^{\circ} \mathrm{C}$ till further use.

\section{Anti-bacterial efficacy test of human breast milk}

- The antibacterial efficacy of breast milk was evaluated using the agar well diffusion assay as per the method of CLSI.

- 4 hour incubated cultures of Staphylococcus aureus S1, S2, S3 and Candida albicans were lawn cultured on to MHA and SDA (For Candida albicans) respectively followed by boring of wells.

- $20 \mu \mathrm{l}$ of raw milk, breast milk, and saline water (control) was added to wells respectively. 
- All the plates were incubated in upright position at $37^{\circ} \mathrm{C}$ for 24 hours.

- After incubation, zones of inhibition were measured.

\section{Result and Discussion}

Isolation

The present study was aimed at evaluating the anti-bacterial properties of human breast milk against pathogens that are commonly associated with infections of new-born and infants. This was done by collecting different clinical specimens from hospitals in the locality. A total of 4 strains isolated from 3 different samples were designated as S1 S2 S3 and F1based on their colony (Table 1-7 and plate 1-12).

S1, S2, S3 were identified as Staphylococcus aureus and F1 were identified as Candida albicans respectively.

\begin{tabular}{|l|c|}
\hline \multicolumn{1}{|c|}{ Clinical samples } & Isolates \\
\hline Ear Swab & S1 \\
\hline Pus swab 1 & S2 \\
\hline Pus swab 2 & S3 \\
\hline Oral swab & F1 \\
\hline
\end{tabular}

Table 1: Different morphology isolates from clinical specimen.

\begin{tabular}{|l|c|}
\hline \multicolumn{1}{|c|}{ Isolate } & Colony morphology \\
\hline S1 & $\begin{array}{c}\text { Small, pin head size, golden yellow, convex } \\
\text { colonies }\end{array}$ \\
\hline S2 & $\begin{array}{c}\text { Small, pin head size, yellow, raised, convex } \\
\text { colonies }\end{array}$ \\
\hline S3 & $\begin{array}{c}\text { Small, pin head size, creamy yellow, convex } \\
\text { colonies }\end{array}$ \\
\hline
\end{tabular}

Table 2: Bacterial colony characteristics.

\begin{tabular}{|l|c|}
\hline \multicolumn{1}{|c|}{ Isolate } & Colony morphology \\
\hline F1 & Large smooth white to cream colony \\
\hline
\end{tabular}

Table 3: Fungal colony characteristics.

\begin{tabular}{|l|c|c|c|}
\hline S.no & Isolates & $\begin{array}{c}\text { Gram } \\
\text { staining }\end{array}$ & Morphology \\
\hline 1. & S1 & + & Cocci in pairs and chains \\
\hline 2. & S2 & + & Cocci in pairs and clusters \\
\hline 3. & S3 & + & Cocci in clusters \\
\hline
\end{tabular}

Table 4: Morphological characterizations of bacterial isolates.

$$
\begin{aligned}
& \text { +: Positive } \\
& \text {-: Negative }
\end{aligned}
$$

\begin{tabular}{|l|c|c|c|c|}
\hline S.no & Isolates & $\begin{array}{c}\text { Gram } \\
\text { staining }\end{array}$ & Morphology & Germ tube \\
\hline 1. & F1 & + & $\begin{array}{c}\text { Oval budding } \\
\text { cells }\end{array}$ & + \\
\hline
\end{tabular}

Table 5: Morphological characterizations of fungal isolate.

$$
\begin{aligned}
& \text { +: Positive } \\
& \text {-: Negative. }
\end{aligned}
$$

\begin{tabular}{|l|c|c|c|c|}
\hline S.no & Isolates & Catalase & Coagulase & $\begin{array}{c}\text { Mannitol salt } \\
\text { agar }\end{array}$ \\
\hline 1. & $\mathrm{~S} 1$ & + & + & + \\
\hline 2. & $\mathrm{~S} 2$ & + & + & + \\
\hline 3. & $\mathrm{~S} 3$ & + & + & + \\
\hline
\end{tabular}

Table 6: Biochemical characterizations of bacterial isolates.

$$
\begin{aligned}
& \text { +: Positive } \\
& \text {-: Negative. }
\end{aligned}
$$

Morphological characters and biochemical reactions of the isolates were studied and finally characterized and identified by following Bergey's Manual of Determinative Bacteriology.

Gram staining reactions of isolates

\begin{tabular}{|l|c|c|}
\hline \multicolumn{1}{|c|}{ S.no } & Isolates & Genera \\
\hline 1. & S1 & Staphylococcus aureus \\
\hline 2. & S2 & Staphylococcus aureus \\
\hline 3. & S3 & Staphylococcus aureus \\
\hline 4. & F1 & Candida albicans \\
\hline
\end{tabular}

Table 7: Identified bacterial and fungal isolates. 


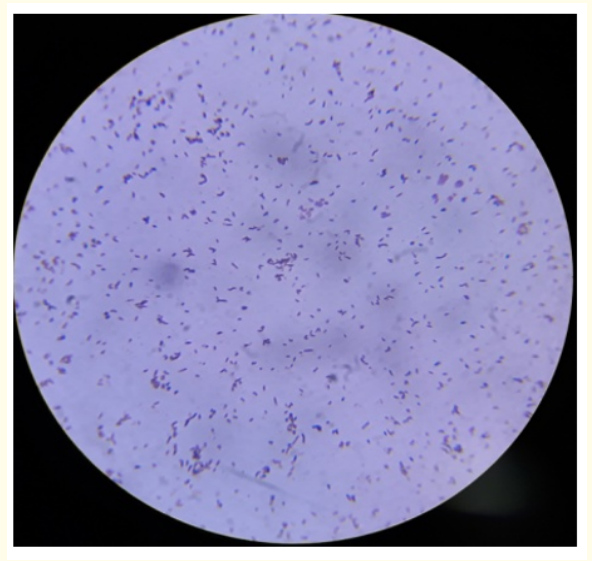

Plate 1: S1.

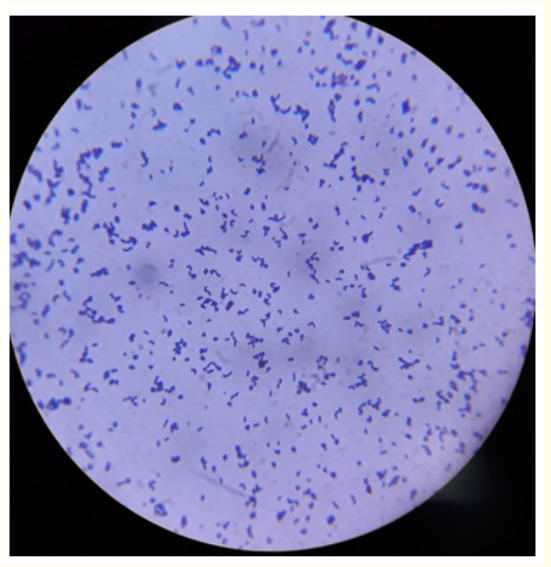

Plate 2: S2.

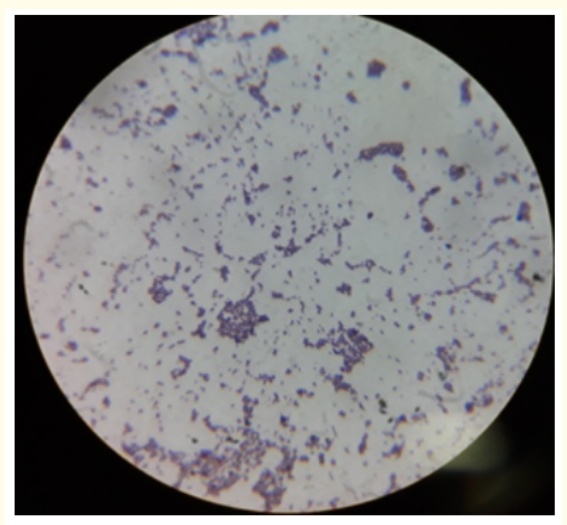

Plate 3: S3.

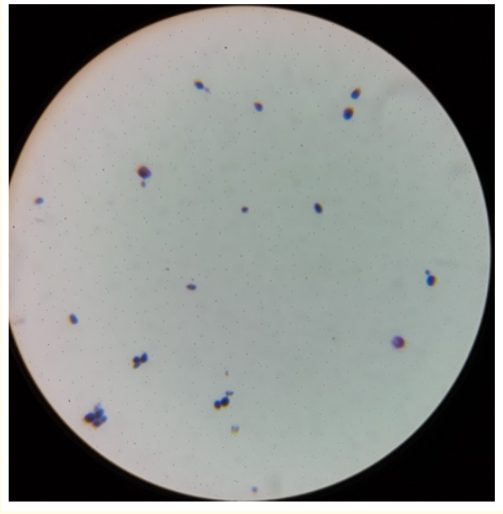

Plate 4: F1.

Germ tube test

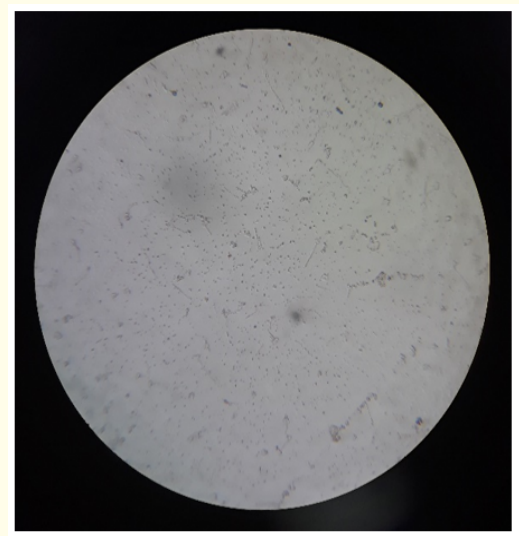

Plate 5: F1.

Bacterial and fungal isolates on suitable media on nutrient AGAR and SDA.

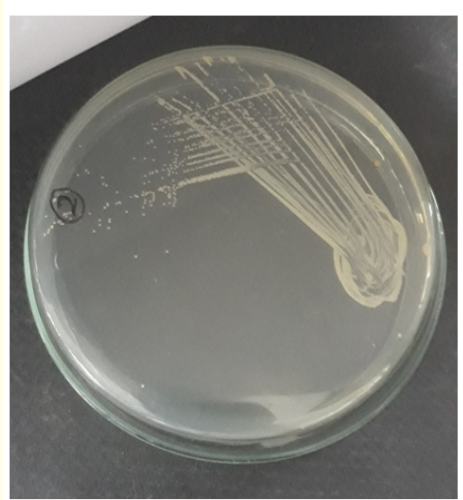

Plate 6: S1. 
On mannitol salt AGAR

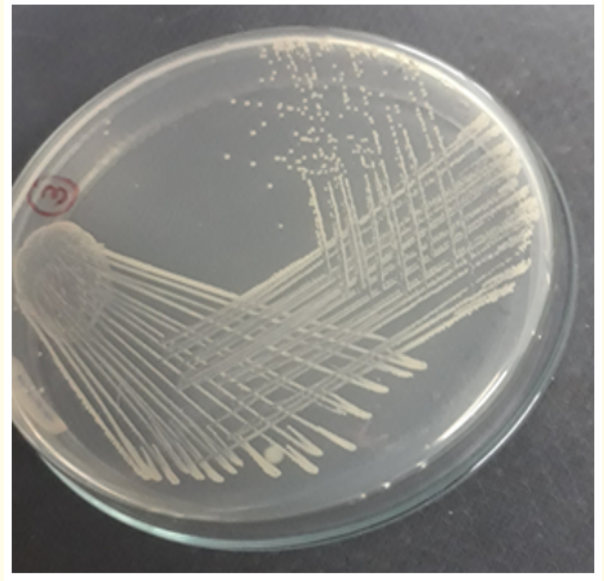

Plate 7: S2.

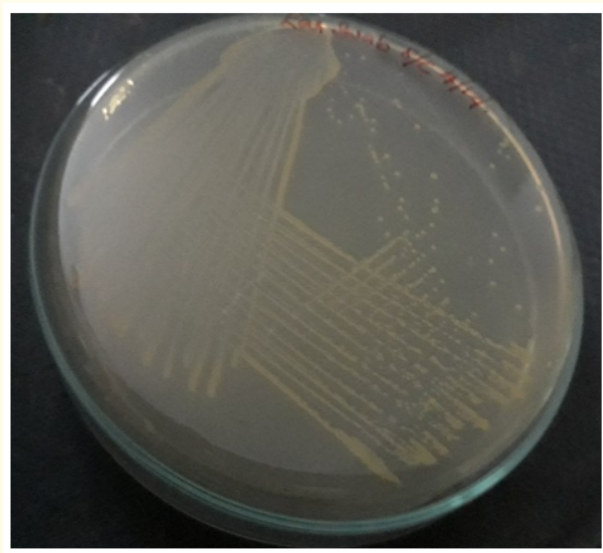

Plate 8: S3.

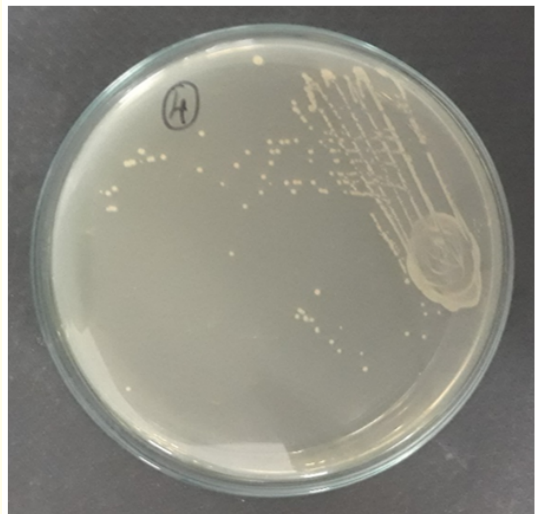

Plate 9: F1.

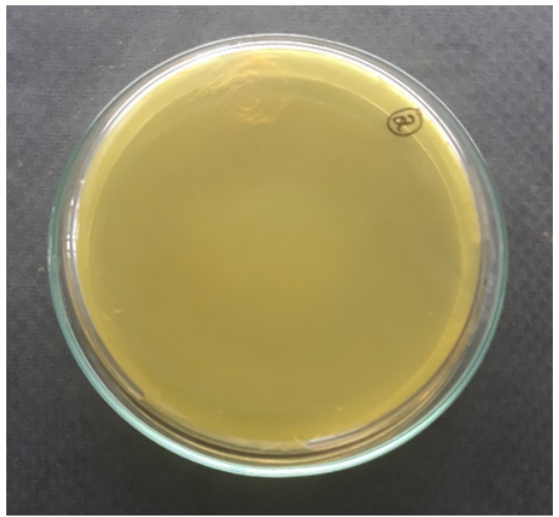

Plate 10: S1.

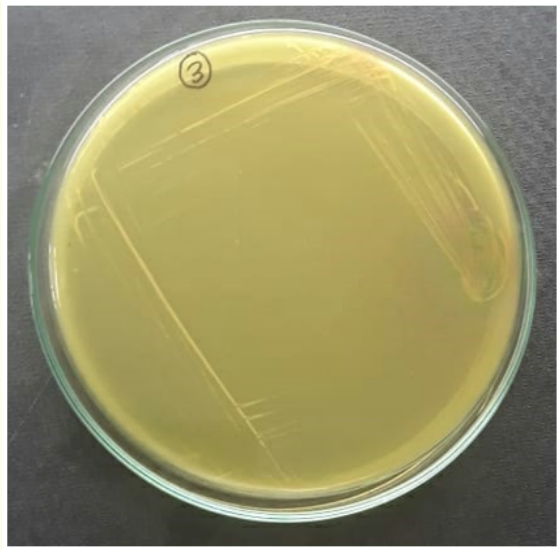

Plate 11: S2.

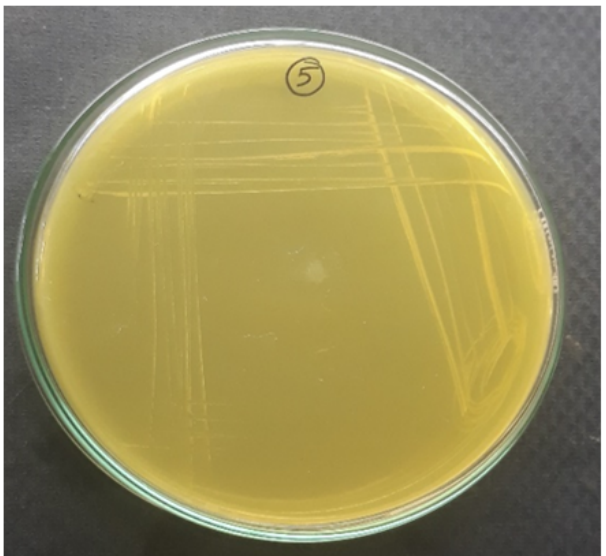

Plate 12: S3. 
Antibiotic activity on bacterial isolates

All the bacterial strains isolated were tested for antibiotic susceptibility test using Kirby bauer method.

All the bacterial isolates were sensitive to both Gentamicin and Rifampicin. However, all the isolates were resistant to Penicillin (Table 8, Plate 13-15).

\begin{tabular}{|l|c|c|c|c|}
\hline Isolate & Penicillin & Gentamicin & Rifampicin & Amoxicillin \\
\hline S1 & $\mathrm{R}$ & $20 \mathrm{~mm}(\mathrm{~S})$ & $26 \mathrm{~mm} \mathrm{(S)}$ & $30 \mathrm{~mm} \mathrm{(S)}$ \\
\hline S2 & $\mathrm{R}$ & $19 \mathrm{~mm}(\mathrm{~S})$ & $30 \mathrm{~mm} \mathrm{(S)}$ & $\mathrm{R}$ \\
\hline S3 & $\mathrm{R}$ & $19 \mathrm{~mm}(\mathrm{~S})$ & $16 \mathrm{~mm} \mathrm{(S)}$ & $\mathrm{R}$ \\
\hline
\end{tabular}

Table 8: Antibiotic susceptibility tests of the bacterial isolates. R: Resistant; S: Sensitive.

\section{On MHA AGAR}

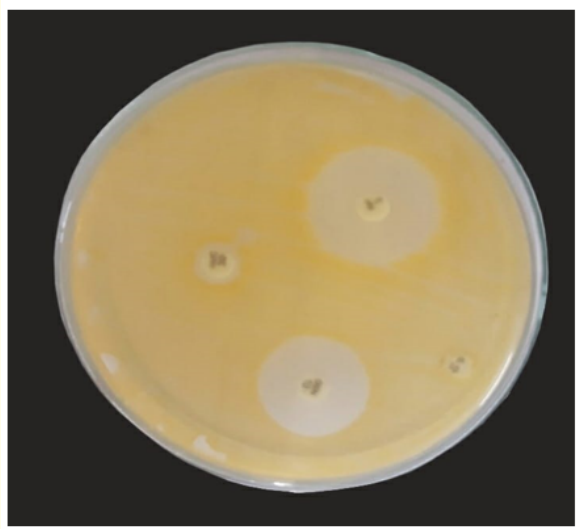

Plate 13: S1.

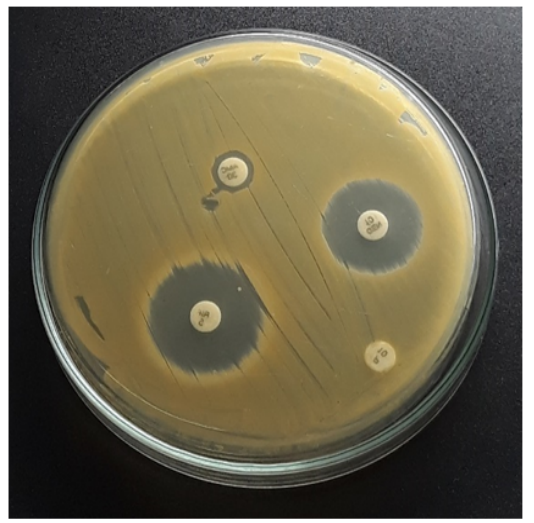

Plate 14: S2.

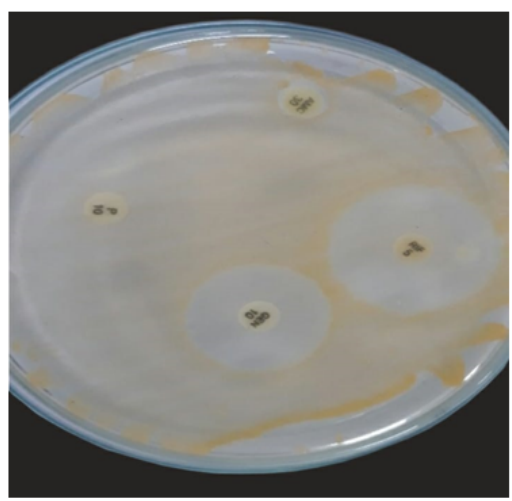

Plate 15: S3.

Anti-bacterial efficacy test of human breast milk and cow milk

The antibacterial efficacy of breast milk and cow milk was evaluated using the agar well diffusion assay as per the method of CLSI.

\begin{tabular}{|l|c|c|c|c|c|c|c|c|c|}
\hline Isolate & BM 1 & BM 2 & BM 3 & BM 4 & BM 5 & BM 6 & BM 7 & RM & Saline \\
\hline S1 & $\begin{array}{c}12 \\
\mathrm{~mm}\end{array}$ & $\begin{array}{c}18 \\
\mathrm{~mm}\end{array}$ & $16 \mathrm{~mm}$ & $\begin{array}{c}20 \\
\mathrm{~mm}\end{array}$ & $\begin{array}{c}18 \\
\mathrm{~mm}\end{array}$ & $\begin{array}{c}19 \\
\mathrm{~mm}\end{array}$ & $\begin{array}{c}20 \\
\mathrm{~mm}\end{array}$ & $\mathrm{R}$ & $\mathrm{R}$ \\
\hline S2 & $\begin{array}{c}14 \\
\mathrm{~mm}\end{array}$ & $\begin{array}{c}16 \\
\mathrm{~mm}\end{array}$ & $20 \mathrm{~mm}$ & $\begin{array}{c}20 \\
\mathrm{~mm}\end{array}$ & $\begin{array}{c}20 \\
\mathrm{~mm}\end{array}$ & $\begin{array}{c}18 \\
\mathrm{~mm}\end{array}$ & $\begin{array}{c}20 \\
\mathrm{~mm}\end{array}$ & $\mathrm{R}$ & $\mathrm{R}$ \\
\hline S3 & $\mathrm{R}$ & $\mathrm{R}$ & $\mathrm{R}$ & $\mathrm{R}$ & $\mathrm{R}$ & $\mathrm{R}$ & $\mathrm{R}$ & $\mathrm{R}$ & $\mathrm{R}$ \\
\hline F1 & $\mathrm{R}$ & $\mathrm{R}$ & $\mathrm{R}$ & $\mathrm{R}$ & $\mathrm{R}$ & $\mathrm{R}$ & $\mathrm{R}$ & $\mathrm{R}$ & $\mathrm{R}$ \\
\hline
\end{tabular}

Table 9: Evaluation of anti-bacterial effect of breast milk and raw milk against the isolates.

- BM 1-7 Showed sensitive to both S1 and S2 And resistance to S3 and F1 isolates.

- Cow milk also showed resistance to all the isolated strains.

Antibacterial activity of breast milk

Antibacterial activity on isolate S1.

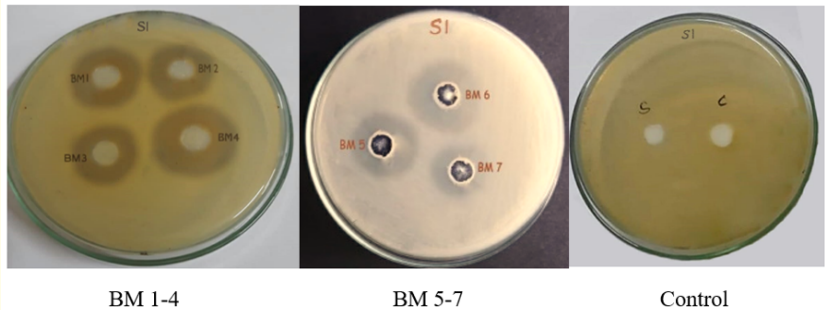

Plate 16 
Antibacterial activity on isolate S2.

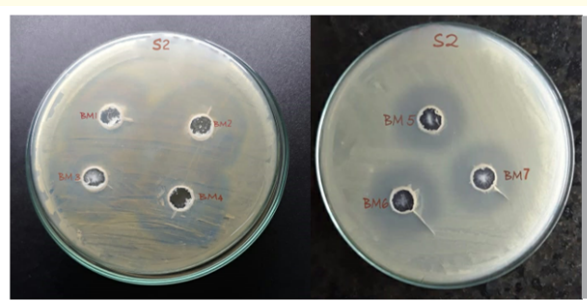

BM 1-4

BM 5-7
Plate 17

Antibacterial activity on isolate S3.

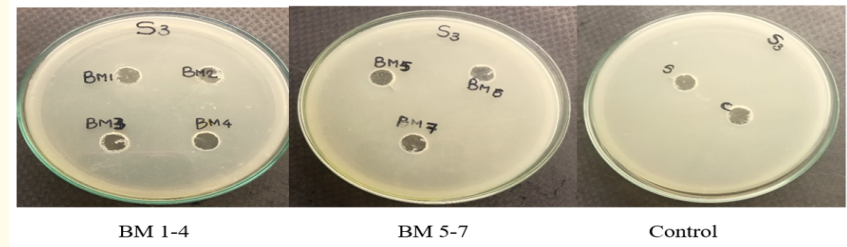

Plate 18

Antimicrobial activity on isolate F1.

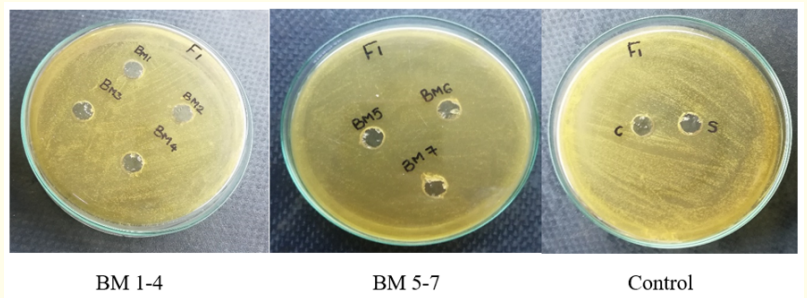

Plate 19

Human breast milk was evaluated for its anti-bacterial effect using agar diffusion assay against three strains of Staphylococcus aureus and Candida albicans. Human breast milk was far more superior in its anti-bacterial effect seen (in terms of zone diameter) than cow milk against all the four strains tested. Breast milk showed largest zone diameter for S. aureus S1 and S2 respectively. Cow milk showed insignificant activity against all the test strains.

In general, there are two mechanisms to explain the inhibitory effect of human breast milk. One is the interaction between specific constitute in milk with epithelial surfaces or with specific substances in the gastrointestinal lumen during digestion of milk while the second mechanism is the possible modulation of infant's immune system by protective factors in the milk which results in selective production of immune factors in the infant [9]. The intrinsic components of milk or partially digested products of human milk, which have local antipathogenic effects that supplement the infant's innate immunity. This includes substances that function as prebiotics such as free fatty acids (FFA), monoglycerides, antimicrobial peptides (AMP), which bind diarrheal pathogens [26].

\section{Conclusion}

- The present work describes the isolation of microorganism from neonatal specimens and their growth in the presence of human breast milk.

- The study reports with the isolation of 3 bacterial strains and 1 fungal strain from different clinical samples.

- These isolates were identified as 3 strains of Staphylococcus aureus and Candida albicans respectively.

- The isolated bacterial cultures were subjected to antibiotic sensitivity test and the results were noted. Gentamicin and Rifampicin showed sensitive to S1, S2 and S3, Amoxicillin was sensitive to $\mathrm{S} 1$ whereas Penicillin and Amoxicillin showed resistance to other isolates.

- The drug Penicillin was resistant to all the three strains of Staphylococcus aureus. This high resistance pattern may be due to injudicious use of the antibiotics and therefore great caution is required in the selection of antibiotics.

- Human breast milk samples and cow milk were collected and tested for their antimicrobial activities against the 4 isolates.

- The zone of inhibition of the isolates were measured and recorded.

- The growth of bacterial isolates S1 and S2 were inhibited by the human breast milk and all the other strains were resistant to the human milk.

- All the strains were resistant to cow milk. 
- The present study can be concluded that the human breast milk can inhibit the growth and survival of some neonatal pathogens.

\section{Acknowledgement}

First and foremost, I bow in profound gratitude to GOD ALMIGHTY for his graceful blessings showered upon us for the successful completion of this work and who has been my strength throughout the course of this project work.

Before I proceed, I would like to add a few heart full words for people who were part of this endeavor in numerous ways and people who gave great support right from the beginning.

I express my deep sense of gratitude to our Rev. Fr. Shaijan M Kalathil, Manager, Presentation College of Applied Sciences, Puthenvelikkara, Ernakulam to allowing me to do this project.

I express my thanks to Mr. Feby FAS, Principal, Presentation College of Applied Sciences Ernakulam for his moral support.

I am ever grateful to Dr. Rashmi P.A (Head of the Department of Microbiology) and Ms.Dayana Joseph (class in charge) and those who supported me during my project work.

It's my privilege to express my sincere gratitude to my guide Ms. Neethu George, Assistant Professor, Department of Microbiology for her valuable help guidance and encouragement rendered to me throughout my project work.

I am thankful to all the teaching and non-teaching staff including lab assistants of the Department of Microbiology for their help, assistance and co-operation.

I thank my friends for their valuable support and help.

Last but not least my heart full thanks to my family whose love, prayers, moral support and encouragement lifted me every time I encountered possibilities.

\section{Bibliography}

1. Ackerman DL., et al. "Antimicrobial and antibiofilm activity of human milk oligosaccharides against Streptococcus agalactiae, Staphylococcus aureus, and Acinetobacter baumannii". ACS Infectious Diseases 4.3 (2017): 315-324.
2. Aftab R and Iqbal I. "Bacteriological agents of neonatal sepsis in NICU at Nishtar Hospital Multan". Journal of the College of Physicians and Surgeons--Pakistan: JCPSP 16.3 (2006): 216-219.

3. Bachrach V R., et al. "Breastfeeding and the risk of hospitalization for respiratory disease in infancy: a meta-analysis". Archives of Pediatrics and Adolescent Medicine 157.3 (2003): 237-243.

4. Berkley J A., et al. "Bacteremia among children admitted to a rural hospital in Kenya". New England Journal of Medicine 352.1 (2005): 39-47.

5. Bhat R., et al. "Bacterial isolates of early-onset neonatal sepsis and their antibiotic susceptibility pattern between 1998 and 2004: an audit from a center in India". Italian Journal of Pediatrics 37.1 (2011): 32 .

6. Chacko B and Sohi I. "Early onset neonatal sepsis". The Indian Journal of Pediatrics 72.1 (2005): 23.

7. Gatchalian S R., et al. "Bacterial and viral etiology of serious infections in very young Filipino infants". The Pediatric Infectious Disease Journal 18.10 (1999): 50S-55S.

8. Hakansson A P. "Protective effects of human milk antimicrobial peptides against bacterial infection". Jornal de pediatria 91.1 (2011): 04-05.

9. Hanson LA., et al. "Breast feeding, a complex support system for offspring". Pediatric International 44 (2002): 347-352.

10. Isaacs C E. "Human milk inactivates pathogens individually, additively, and synergistically". The Journal of Nutrition 135.5 (2005): 1286-1288.

11. JC Cappucino. Microbiology: a laboratory manual/James G. Cappuccino, Natalie Sherman. $10^{\text {th }}$ edition.

12. Kaistha N., et al. "Neonatal septicemia isolates and resistance patterns in a tertiary care hospital of North India". The Journal of Infection in Developing Countries 4.1 (2009): 055-057.

13. Khadduri R., et al. "Household knowledge and practices of newborn and maternal health in Haripur district, Pakistan". Journal of Perinatology 28.3 (2008): 182.

14. Klein J 0. "Infectious diseases of the fetus and newborn infant" (2001): 943-948. 
15. Lawrence R M. "Human breast milk: current concepts of immunology and infectious diseases". Current Problems in Pediatric and Adolescent Health Care 37 (2007): 7.

16. Lessen R and Kavanagh K. "Position of the academy of nutrition and dietetics: promoting and supporting breastfeeding". Journal of the Academy of Nutrition and Dietetics 115.3 (2015): 444-449.

17. Mercy T C. "Neonatal sepsis". National institute of health, online medical library (2009).

18. Milledge J., et al. "Aetiology of neonatal sepsis in Blantyre, Malawi: 1996-2001". Annals of Tropical Paediatrics 25.2 (2005): 101-110.

19. Morrow A L., et al. "Human milk oligosaccharides are associated with protection against diarrhea in breast-fed infants". The Journal of Pediatrics 145.3 (2004): 297-303.

20. Oddy WH. "Infant feeding and obesity risk in the child". Breastfeeding Review 20.2 (2012): 7-13.

21. Polin R A. "The "ins and outs" of neonatal sepsis". The Journal of Pediatrics 143.1 (2003): 3-4.

22. Puccio G., et al. "Effects of infant formula with human milk oligosaccharides on growth and morbidity: a randomized multicenter trial". Journal of Pediatric Gastroenterology and Nutrition 64.4 (2017): 624.

23. Qazi S A and Stoll B J. "Neonatal sepsis: a major global public health challenge". The Pediatric Infectious Disease Journal 28.1 (2009): S1-S2.

24. Sadeharju K., et al. "Maternal antibodies in breast milk protect the child from enterovirus infections". Pediatrics 119.5 (2007): 941-946.

25. Sahai S., et al. "Childhood bacterial meningitis in Pondicherry, south India". The Indian Journal of Pediatrics 68.9 (2001): 839841

26. Salminen S J., et al. "Probiotics that modify disease risk". The Journal of Nutrition 135.5 (2005): 1294-1298.

27. Savino F., et al. "Advances on human milk hormones and protection against obesity". Cellular and Molecular Biology 59.1 (2013): 89-98.
28. Sawhney N., et al. "Bacteriological profile and antibiotic susceptibility pattern of neonatal septicaemia in a tertiary care hospital". International Journal of Current Microbiology and Applied Sciences 4.10 (2016): 977-984.

29. Sundaram V., et al. "Blood culture confirmed bacterial sepsis in neonates in a North Indian tertiary care center: changes over the last decade". Japanese Journal of Infectious Diseases 62.1 (2009): 46-50.

30. Tromp I., et al. "Breastfeeding and the risk of respiratory tract infections after infancy: The Generation R Study". PloS One 12.2 (2017): e0172763.

31. World Health Organization. "Neonatal and perinatal mortality: country, regional and global estimates" (2006).

32. Zaidi A K., et al. "Hospital-acquired neonatal infections in developing countries". The Lancet 365.9465 (2005): 1175-1188.

33. Zakariya B P., et al. "Neonatal sepsis in a tertiary care hospital in South India: bacteriological profile and antibiotic sensitivity pattern". The Indian Journal of Pediatrics 78.4 (2011): 413-417.

\section{Assets from publication with us}

- Prompt Acknowledgement after receiving the article

- Thorough Double blinded peer review

- Rapid Publication

- Issue of Publication Certificate

- High visibility of your Published work

Website: www.actascientific.com/

Submit Article: www.actascientific.com/submission.php

Email us: editor@actascientific.com

Contact us: +919182824667 